\title{
Research Article \\ Research Method of Tyre Contact Characteristics Based on Modal Analysis
}

\author{
Bo Li, Shaoyi Bei, and Jingbo Zhao \\ School of Automobile and Traffic Engineering, Jiangsu University of Technology, Changzhou 213001, China \\ Correspondence should be addressed to Bo Li; czblfly@sina.com
}

Received 21 August 2016; Revised 1 November 2016; Accepted 6 November 2016; Published 17 January 2017

Academic Editor: Evangelos J. Sapountzakis

Copyright (C) 2017 Bo Li et al. This is an open access article distributed under the Creative Commons Attribution License, which permits unrestricted use, distribution, and reproduction in any medium, provided the original work is properly cited.

\begin{abstract}
Tyre is the only connecting part between the vehicle and the road, which provides all the vehicle driving, steering, and braking force. Accuracy tyre dynamics models are increasingly needed. Because of the structure nonlinear and complexity of contact state, how to establish effective tyre model is always the difficulty of vehicle dynamics modeling. Based on the idea of modal parameters modeling, establish the quantitative static tyre model in the vertical direction and research the effects of modal root and tread model on this method. With the tyre vertical load on the road, research the pressure and deformation features in the tyre contact patch and the interrelation between the horizontal load distribution, contact length, and sinking amount. Use the iterative method to establish tyres static vertical model on the horizontal road. The theoretical calculation and experiment results indicate the relation curves of vertical force distribution and sinking amount, vertical load, and length of contact patch and show good agreement on the qualitative and quantitative aspects.
\end{abstract}

\section{Introduction}

Tyre is one of the important components in the vehicle, and its mechanical properties and structure design directly affect the driving performance of vehicle. Tyre is the only support and force transmission element to connect vehicle and road. Tyre mechanics is the basis of vehicle dynamics and the further development of vehicle dynamics and control technology relies on the precise tyre modeling techniques [1-3]. During the running process of the vehicle, in addition to the force of air resistance, the other forces and torques on the car are all through the function of the tyre, so the most important mechanical properties of a car have close relationship with the mechanical properties of the tyre. As we all know, the vertical dynamic characteristics of tyre determines the ride comfort of vehicle; under the different vertical loads and speed conditions, aligning torque changes with the longitudinal slip rate and side slip angle and affects cornering properties and camber characteristics which determine vehicle handling stability and safety; tyre rolling resistance, adhesion, and enveloping properties all affect vehicle braking and driving performance, reliability, and fuel economy [4-6].
For a long time, scholars have conducted extensive research and exploration on the tyre model. According to the modeling methods, tyre model can be divided into empirical models [7-9], analytical model, and finite element model [10, 11]. Finite element model can provide a more accurate input of tyre structure parameters and material properties, whose result is accurate, but due to the large amount of calculation, occupying large computer resources, finite element model is still difficult for vehicle dynamics simulation and often used for product development and design.

In the process of car driving, the tyre has a periodic force from the road, so the rolling characteristics are related to its frequency and vibration mode [12], and the frequency and mode of vibration are the key factors for the tyre modal [13-15]. According to the different research methods and means, modal analysis can be divided into theoretical modal analysis and experimental modal analysis [16-18]. With the system mass, damping, and stiffness matrix of modal parameters, calculate and analyze the relationship between excitation, system, and response and finally study the dynamic response characteristics of system structure; experimental modal analysis is supported by stimulus and 


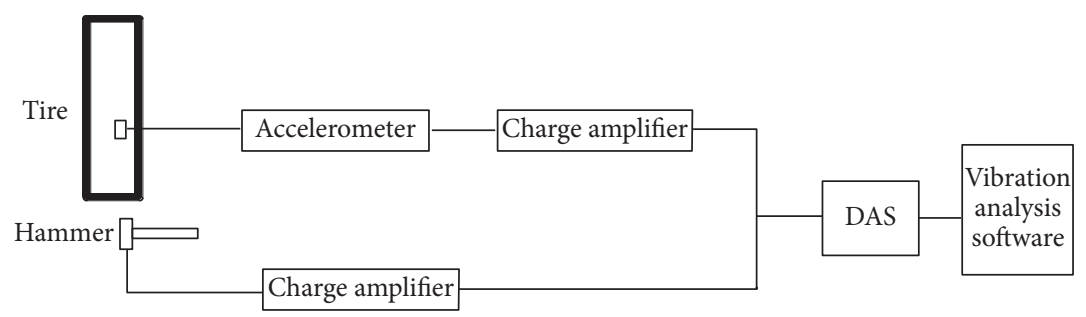

FIGURE 1: Experimental modal flow chart.

response system by measuring the time course of the experiment, using digital signal processing techniques to obtain the frequency response function or impulse response function to get a nonparametric model of the system, and then using the parameter identification method to obtain the modal system parameters and to further determine the physical parameters of the system. Therefore, the experimental modal analysis is a process of comprehensive disciplines and techniques for system identification. Based on the theory of modal parameter modeling, combining with relevant literature, this paper establishes a quantitative static vertical tyre model, analyzes vertical load of tyre on the horizontal surface and the relationship between vertical force distribution, load, length, and sinking amount in contact patch, and constructs the static vertical model on the horizontal road by using iterative method.

\section{Experimental Method}

General experimental modal analysis system includes excitation systems, signal measurement acquisition, and analysis system. With modal analysis theory, input and output signals can be got through modal test methods; then frequency response function of the system can be solved [19-21].

Excitation input is got by hammer knocking tyre and then using charge amplifier to import data acquisition and processing system. By the time domain and frequency domain analysis to obtain data modal identification and verification, finally, the natural frequencies, damping ratios, and vibration modes of the tested tyre are obtained; experimental modal flow chart is shown in Figure 1.

\section{Modal Theory for Tyre Model}

By using test method to obtain tyre steady vertical model of modal parameters, analyze the sinking amount, contact length, force deformation, and stress distribution caused by the vertical load $[13,14]$. Deformation of carcass is the main reason for sinking amount and is also the key factor for the overall elastic deformation of tyre, and its force deformation characteristics are embodied in the modal parameters. According to Guan Dihua rolling theory based on modal parameters, establish the force and deformation model of tyre carcass and tread $[20,21]$.

During the rolling process of the tyre, the tyre and road surface are in contact with each other, and the interaction force between the horizontal and the vertical directions is generated. It is assumed that the tyre is a driven wheel and assuming that the axle is only subjected to horizontal driving force and vertical gravity and does not bear the driving and braking torque, it rolls at a constant speed on a horizontal rigid road surface. As the tread width is not included in the tyre rolling model, the longitudinal and vertical characteristics of the contact patch are the focus. The tyre needs to be uniformly dispersed in the circumferential direction, and the rolling trace should be divided into $n$ units uniformly and analyze the forces of the elements in the contact patch.

The tyre is divided into two parts: the carcass and the tread, with connecting each other in series. The deformation and force of each part are deduced as follows.

3.1. Carcass Deformation Model. Assume carcass deformation:

$$
\begin{aligned}
& b_{r}=H_{r r} f_{r}+H_{\mathrm{i}} f_{t} \\
& b_{t}=H_{r t} f_{r}+H_{t t} f_{t} .
\end{aligned}
$$

In equation,

$b_{r}, b_{t}$ is carcass radial deformation vector and vector tangential deformation vector;

$H_{r r}$ is radial response transfer function of radial excitation;

$H_{t r}$ is radial response transfer function of tangential excitation;

$H_{r t}$ is tangential response transfer function of radial excitation;

$H_{t t}$ is tangential response transfer function of tangential excitation;

$f_{r}$ is radial force;

$f_{t}$ is tangential force;

$t, r$ is carcass tangential and radial component.

Then, derivate $i$ point response function under $j$ point excitation:

$$
\begin{aligned}
& b_{i j}(t)=\int_{0}^{t} \sum_{k=1}^{N} \frac{\varphi_{j k}^{r r} \varphi_{i k}^{r r}}{w_{d k}} e^{-\xi_{n} w_{k}(t-\tau)} \\
& \cdot \cos \left(\frac{V(t-\tau)}{R}\right) \sin w_{d k}(t-\tau) f_{j} d \tau .
\end{aligned}
$$


In equation,

$$
f_{j} \text { is } j \text { point exciting force; }
$$

$\varphi_{j k}^{r r}$ is $j$ point $k$ order modal coefficients of radial excitation;

$\varphi_{i k}^{r r}$ is $i$ point $k$ order modal coefficients of radial excitation;

$\xi_{k}$ is order damping ratio of $k$ order;

$w_{d k}$ and $w_{k}$ are undamped modal frequency and damping modal frequencies of $k$ order.

According to the symmetry of the tyre, relationship between $\varphi_{j k}^{r r}$ and $\varphi_{i k}^{r r}$ is as follows:

$$
\varphi_{j k}^{r r}=\varphi_{i k}^{r r} \cos (k \theta+\theta)
$$

Assume $h_{i j}=\left(e^{-\xi_{k} w_{k} t} \varphi_{j k}^{r r} \varphi_{i k}^{r r} / w_{d k}\right) \sin \left(w_{d k} t\right)$; then crossresponse function of $i$ point

$$
b_{i j}(t)=\int_{0}^{t} \sum_{k=1}^{N} h_{i j} \cos \left(\frac{V(t-\tau)}{R}\right) f_{j} d \tau
$$

With the tyre rolling on the horizontal smooth surface and its response being the model superposition results of all orders, then the response function of $i$ point is as follows:

$$
b_{i j}(t)=\int_{0}^{t} \sum_{k=1}^{N} h_{i j} \cos \left(k \frac{V(t-\tau)}{R}\right) f_{j} d \tau \text {, }
$$

therefore, solve $H_{\mathrm{rr}}=\int_{0}^{t} \sum_{k=1}^{N} h_{i j} \cos (k(V(t-\tau) / R)) d \tau$ and each coefficient of $H$ matrix in the same way.

Assuming undamped tread, tread deformation can be represented:

$$
\begin{aligned}
& t_{n}=\frac{f_{n}}{k_{r}}, \\
& t_{m}=\frac{f_{m}}{k_{t}}
\end{aligned}
$$

In equation

$k_{t}$ and $k_{r}$ are tangential and radial stiffness of the tread;

$t_{m}$ and $t_{n}$ are tangential and radial deformation of the tread.

Since the tread comprises rubber damping material, use the relationship between shear modulus and elastic modulus to establish the expression of tread stiffness.

$$
G^{\prime}=E_{t r}+i G_{t r}
$$

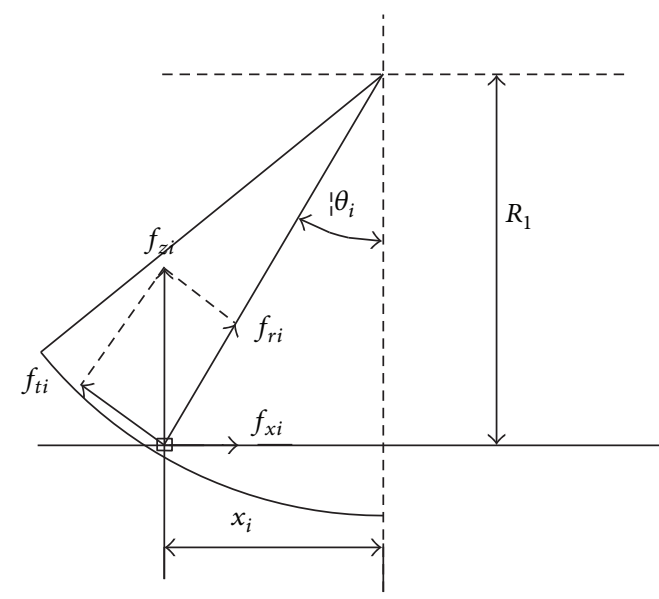

FiguRE 2: Discrete units force condition within contact patch.

Define hysteresis tread as

$$
\tan \delta=\frac{G_{t r}}{E_{t r}}
$$

where $G_{t r}$ is shear modulus of tread and $E_{t r}$ is elastic modulus of tread.

Define displacement admittance expression of tread elements

$$
\begin{aligned}
H_{h} & =(k+j w c)^{-1}, \\
c & =\left[\begin{array}{l}
c_{r} \\
c_{t}
\end{array}\right]=\left[\begin{array}{c}
K_{r} \\
K_{t}
\end{array}\right] \frac{\tan \delta}{\Omega}
\end{aligned}
$$

Then, expression of tread deformation is as follows:

$$
\begin{aligned}
& t_{n}=f_{n} \frac{\left(1-e^{\left(-K_{r} / c \cdot t\right)}\right)}{K_{r}}, \\
& t_{m}=f_{m} \frac{\left(1-e^{\left(-K_{r} / c \cdot t\right)}\right)}{K_{t}} .
\end{aligned}
$$

3.2. Tyre Force Model. Along the circumferential direction, the tyre is divided into discrete units; then, the whole analysis is carried on. As in Figure 2, divide the contact patch to $n$ discrete units, where resultant of forces is shown as

$$
\begin{aligned}
& F_{x}=\sum_{i=1}^{n} f_{x i}, \\
& F_{z}=\sum_{i=1}^{n} f_{z i} .
\end{aligned}
$$

According to the horizontal force $f_{x i}$ and vertical force $f_{z i}$ of discrete element $i$ in contact patch, then, solve $i$ point radial force $f_{r i}$ and tangential force $f_{t i}$; the corresponding expression is as follows:

$$
\begin{gathered}
f_{r i}=f_{z i} \cos \theta_{i}+f_{x i} \sin \theta_{i}, \\
f_{t i}=f_{z i} \sin \theta_{i}-f_{x i} \cos \theta_{i} .
\end{gathered}
$$




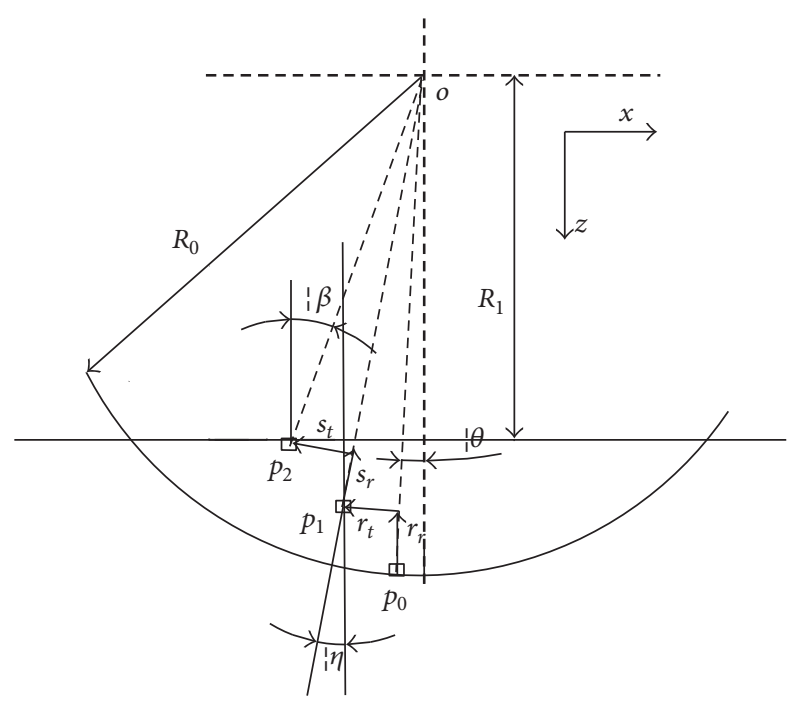

Figure 3: Force and deformation of tyre.

3.3. Tyre Deformation Model. With modal parameter model, tyre is divided into carcass and tread, which form series model [20]. While tyre rolling, the deformation between tyre and road under the interaction force is as shown in Figure 3.

$p_{0}$ is one point in the tread and moves to $p_{1}$ after the radial deformation $r_{r}$ and tangential deformation $r_{t}$ of the tread and then moves to $p_{2}$ after the radial deformation $s_{r}$ and tangential deformation $s_{t}$ of the carcass; $\eta$ is the angle between the radial and vertical direction of $p_{1}$ point and $\beta$ is the angle between the radial and vertical direction of $p_{2}$ point. That is to say, $p_{0}, p_{1}$, and $p_{2}$ are the same point of tread, but of different coordinate positions; first of all, with the deformation of tread, $p_{0}$ moves to $p_{1}$ and then with the deformation of carcass, $p_{1}$ moves to $p_{2}$, which means that $p_{0}$ moving to $p_{2}$ has two steps (deformation of carcass and tread).

After the deformation of tread and carcass, $p_{0}$ moves to $p_{2}$; the superposition relationship between the displacement vector can be solved as

$$
\overrightarrow{o p_{0}}+\overrightarrow{p_{0} p_{1}}+\overrightarrow{p_{2} p_{2}}=\overrightarrow{o p_{2}}
$$

After coordinate transformation, (13) can be expressed:

$$
\begin{aligned}
x_{p_{2}}= & \left(R_{0}-r_{r}-s_{r}\right) \sin \theta+\left(r_{t}+s_{t}\right) \cos \theta-s_{r} \sin \eta \\
& +s_{t} \cos \eta, \\
z_{p_{2}}= & \left(R_{0}-r_{r}-s_{r}\right) \cos \theta-\left(r_{t}+s_{t}\right) \sin \theta-s_{r} \cos \eta \\
& -s_{t} \sin \eta .
\end{aligned}
$$

Further elucidate the relationship between tread element deformation and carcass element deformation:

$$
\begin{aligned}
s_{r}= & -z_{p 2} \cos \eta-x_{p 2} \sin \eta+\left(R_{0}-r_{r}\right) \cos (\theta-\eta) \\
& +r_{t} \sin (\theta-\eta) \\
s_{t}= & -z_{p 2} \sin \eta+x_{p 2} \cos \eta-\left(R_{0}-r_{r}\right) \sin (\theta-\eta) \\
& -r_{t} \cos (\theta-\eta) .
\end{aligned}
$$

Analyze the mechanical components of tread elements in different coordinates:

$$
\begin{aligned}
& F_{z}=f_{s r} \cos (\eta)+\sin (\eta) f_{s t} \\
& F_{x}=-\sin (\eta)+\cos (\eta) f_{s t}
\end{aligned}
$$

where, $f_{s t}, f_{s r}, F_{z}$, and $F_{x}$ are tangential force, radial force, vertical force, and horizontal force.

Analyze the relationship between carcass tangential force $f_{r t}$ and radial force $f_{r r}$ :

$$
\begin{aligned}
& f_{r r}=\cos (\theta-\eta) f_{s r}+\sin (\theta-\eta) f_{s t}, \\
& f_{r t}=-\sin (\theta-\eta) f_{s r}+\cos (\theta-\eta) f_{s t} .
\end{aligned}
$$

Define vertical force and horizontal force in the contact patch as $F_{z 0}$ and $F_{x 0}$, with iterative method and (17), tread tangential forces $f_{s t}$, and radial force $f_{s r}$ :

$$
\begin{aligned}
& f_{s r}=f_{z 0} \cos (\eta)-\sin (\eta) f_{x 0}, \\
& f_{s t}=\sin (\eta) f_{z 0}+\cos (\eta) f_{x 0} .
\end{aligned}
$$

With (17) and (18), carcass tangential force $f_{r t}$ and radial force $f_{r r}$ are as follows:

$$
\begin{aligned}
f_{r r} & \\
\qquad & f_{z 0}[\cos (\eta) \cos (\theta-\eta)+\sin (\theta-\eta) \sin (\eta)] \\
& \quad+f_{x 0}[-\cos (\theta-\eta) \sin (\eta)+\sin (\theta-\eta) \cos (\eta)] \\
& \\
f_{r t} & \\
= & f_{z 0}[-\sin (\theta-\eta) \cos (\eta)+\cos (\theta-\eta) \sin (\eta)] \\
& +f_{x 0}(\sin (\theta-\eta) \sin (\eta)+\cos (\theta-\eta) \cos (\eta)) .
\end{aligned}
$$

\section{Experimental Procedure and Results Analysis}

4.1. Modal Experiment. As the test object, tyre is placed on the soft sponge support, using mobile hammer method to get tyre excitation with 12 pick-up point around the tyre center; the test equipment is shown in Table 1; test process is shown in Figures 4(a), 4(b), 4(c), and 4(d) and the modal frequency and damping ratio are shown in Table 2. Those test data are for the next step to construct tyre modal parameters of contact model.

From the results of the modal test, it is known that the vibration mode of the tyre is characterized by harmonic wave. 
TABLE 1: Test equipment.

\begin{tabular}{|c|c|c|c|}
\hline Number & Tool type & $\begin{array}{l}\text { Configuration } \\
\text { instruction }\end{array}$ & $\begin{array}{l}\text { Factory } \\
\text { number }\end{array}$ \\
\hline 1 & DASP-V10 & $\begin{array}{l}\text { Multichannel signal } \\
\text { acquisition and real-time } \\
\text { analysis software }\end{array}$ & $2240-2014$ \\
\hline 2 & Poly LSDF & $\begin{array}{l}\text { Poly LSDF modal } \\
\text { analysis software }\end{array}$ & \\
\hline 3 & MIMO & $\begin{array}{l}\text { Test and analysis } \\
\text { software of multi-input } \\
\text { and multioutput modals }\end{array}$ & \\
\hline 4 & INV3060S & $\begin{array}{l}24 \text { bit intelligent } \\
\text { collecting instrument of } \\
\text { network type }\end{array}$ & A0B0A006 \\
\hline 5 & $\begin{array}{c}\text { MSC-3 } \\
\text { (ICP/LEM0) }\end{array}$ & Medium-sized hammer & YD-5T-140309 \\
\hline 6 & INV9832A & $\begin{array}{l}\text { Three-dimensional } \\
\text { acceleration vibration } \\
\text { sensor }\end{array}$ & 140509 \\
\hline
\end{tabular}

TABLE 2: Modal frequency and damping ratio of each order.

\begin{tabular}{lccc}
\hline Type & Number & Frequency $(\mathrm{Hz})$ & Damping ratio (\%) \\
\hline & 1 & 112.839 & 4.528 \\
& 2 & 113.661 & 3.958 \\
& 3 & 125.580 & 5.220 \\
& 4 & 133.580 & 3.528 \\
SF-350 & 5 & 135.528 & 3.666 \\
230/60R14 & 6 & 155.739 & 3.370 \\
& 7 & 156.657 & 2.766 \\
& 8 & 180.092 & 3.198 \\
& 9 & 182.454 & 3.972 \\
& 10 & 207.977 & 3.180 \\
& 11 & 210.787 & 3.920 \\
& 12 & 238.917 & 3.166 \\
& 13 & 241.519 & 2.780 \\
& 14 & 250.064 & 0.193 \\
& 15 & 274.594 & 3.417 \\
& 16 & 312.030 & 3.779 \\
\hline
\end{tabular}

When performing function fitting with trigonometric series, use the least squares method to determine the undetermined coefficients; therefore,

$$
y_{i}=A_{0}+\sum_{j=1}^{n}\left(A_{j} \cos (j x)+B_{j} \sin (j x)\right), \quad n<m,
$$

where, $A_{0}, A_{j}$, and $B_{j}$ are the undetermined coefficients; $n$ is the order.

There are $2 n+1$ undetermined coefficients in (20) and $2 m$ points $\left(x_{i}, y_{i}\right)$ from the model test; while method of least squares is used to fitting function, the precondition must be $(2 n+1)<2 m$; if there are 12 points $\left(x_{i}, y_{i}\right)$, then $n=5$.
With least squares method for the undetermined coefficients, the result should be

$$
\begin{aligned}
A_{0} & =\frac{\sum_{i=0}^{m} E_{j}}{2 m}, \\
A_{j} & =\frac{\sum_{i=0}^{m} E_{i} \cos j x_{i}}{m}, \\
B_{j} & =\frac{\sum_{i=0}^{m} G_{i} \sin j x_{i}}{m} .
\end{aligned}
$$

The description for undetermined coefficients obtained by fitting function is as follows: with the model test results of tyre, modal shapes are all symmetric harmonic, so, in most cases with the specific order, some $A_{j}$ should have predominance with the same direction for excitation and response under some modal shape; some $B_{j}$ should have predominance with the opposite direction for excitation and response under some modal shape; other undetermined coefficients can be neglected.

With the above steady vertical model of modal parameters, solve contact patch length, pressure, deformation, and sinking amount of tyre on rigid horizontal surface under static load; the analysis results are shown in Figures 5 and 6.

Figure 5 shows the vertical pressure distribution and length in contact patch, under three vertical loads $(2.1 \mathrm{kN}$, $5.4 \mathrm{kN}$, and $8.3 \mathrm{kN})$. Under the low vertical load $(2.1 \mathrm{kN})$, the vertical pressure distribution of contact patch presents "sharp" parabolic shape; there is about $70 \mathrm{~mm}$ contact patch length. Under the middle vertical load $(5.4 \mathrm{kN})$, the vertical pressure distribution of contact patch presents ladder and gets a slight decrease in the center part; there is about $110 \mathrm{~mm}$ contact patch length. Under the vertical load $(8.3 \mathrm{kN})$, the vertical pressure distribution of contact patch presents ladder; there is about $130 \mathrm{~mm}$ contact patch length. The numerical simulation results of modal parameter for contact features have consistency with the contact test results in Table 3 of footprint length.

The self-developed test bench is shown in Figure 7. The blue part of the figure is the tire, and the red dot is the wheel axle which transfers the vertical load from the test beach to the wheel. Using pressure-sensitive film for the contact footprint test, the specific experiment steps are as follows:

(1) Clean up dirt debris and other contaminants on the tyre surface.

(2) Put the tyre on the test bench.

(3) Mark the required test points on the tyre sidewall.

(4) According to GB/T521, measure the outer diameter and section width of tyre.

(5) Place the pressure-sensitive film between tread and simulation platform, and apply vertical radial load to tyre axle at a constant speed and keep pressuresensitive film without wrinkle, holding more than 2 minutes after loading, and then measure the static load radius and section width.

(6) Process data by pressure-sensitive film. 


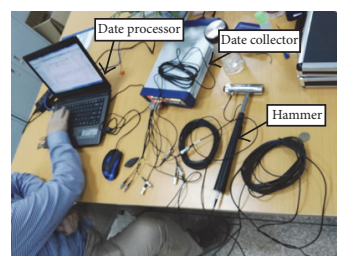

(a) DASP test equipment

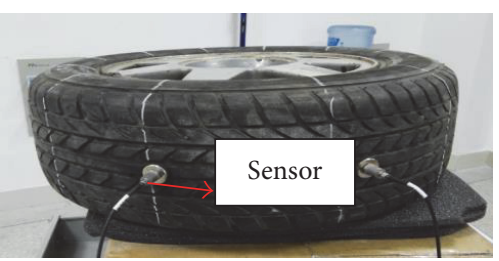

(b) Test process

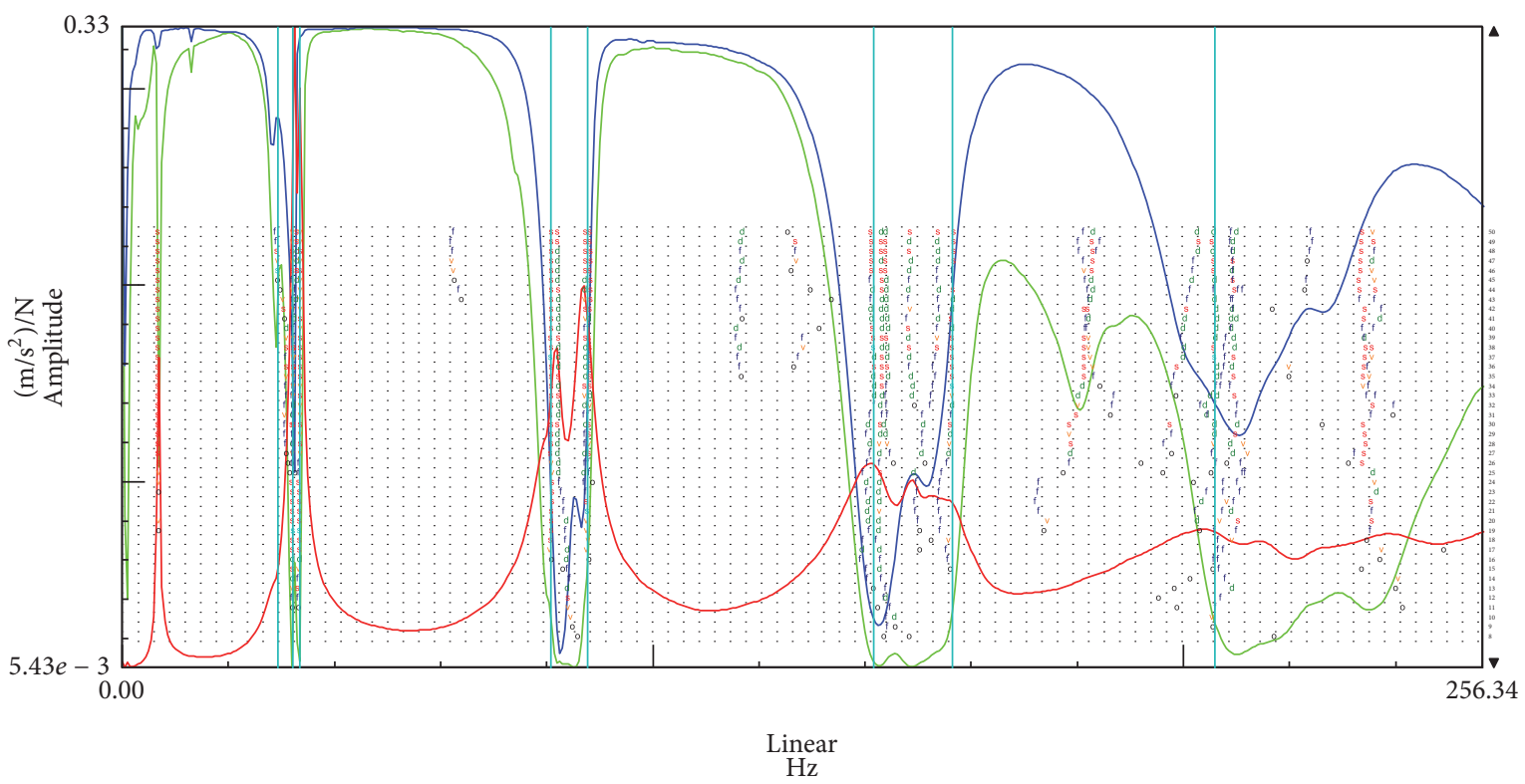

(c) Steady-state diagram of frequency response function

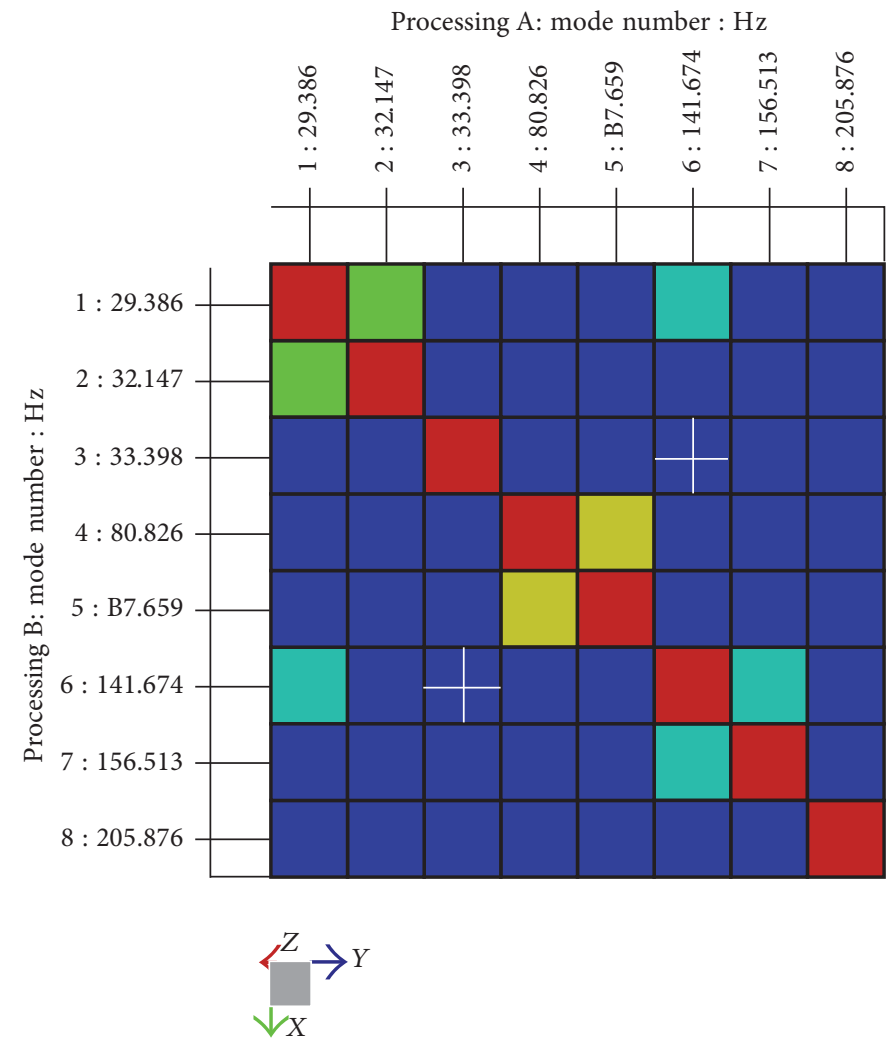

(d) Frequency and orthogonal mode of the multiple root

FIGURE 4: Modal test and analysis. 
TABLE 3: Results for contact patch test.

\begin{tabular}{|c|c|c|c|c|}
\hline Vertical load/N & $\begin{array}{l}\text { Sinking amount } \\
\mathrm{mm}\end{array}$ & $M / \mathrm{mm}$ & $L / \mathrm{mm}$ & Contact patch \\
\hline 2131 & 8 & 104 & 86 & \\
\hline 3261 & 12 & 123 & 112 & \\
\hline 5478 & 20 & 142 & 117 & \\
\hline 6502 & 23 & 146 & 126 & \\
\hline 7322 & 26 & 147 & 132 & \\
\hline 8321 & 29 & 149 & 135 & \\
\hline
\end{tabular}

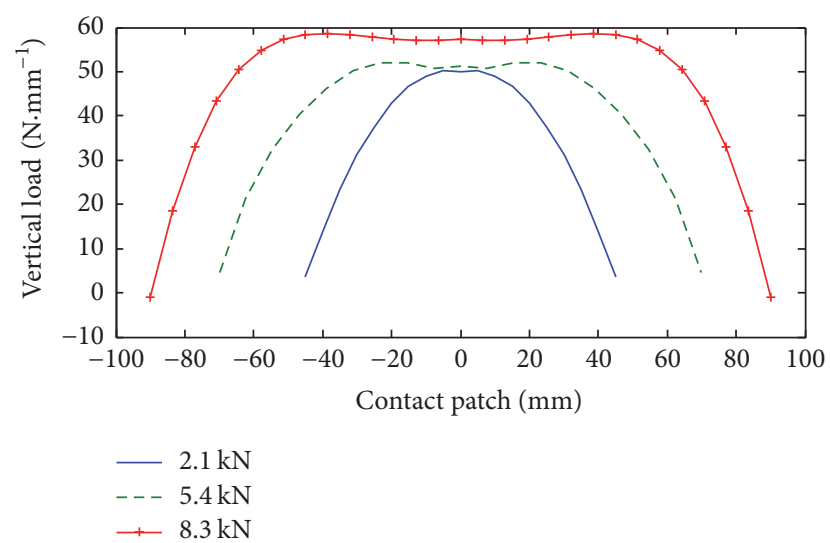

FIGURE 5: Vertical pressure distribution.

In order to regulate the tyre contact patch measurement, the coordinate system is defined in Figure 8; $L$ is the length of the contact patch, $M$ is the width of the contact patch, $X$ is the longitudinal direction of the contact patch, and $Y$ is the lateral direction of the contact patch.

After processing data, the original measurement data are shown in Table 3. In terms of the average ground contact pressure, the contact patch length and width increase as the vertical load increases. It can be seen that the calculation results of modal parameters have certain consistency with the ones of test bench on contact patch length and sinking amount. Figure 9 shows the comparison of sinking amount and vertical load between the theory results and experiment results, and it can be shown that the vertical stiffness basically remains unchanged between $2131 \mathrm{~N}$ and $8321 \mathrm{~N}$.

\section{Conclusions}

With the rolling theory based on modal parameters, the force and deformation model of tyre carcass and tread is established. By using test method to obtain tyre steady 


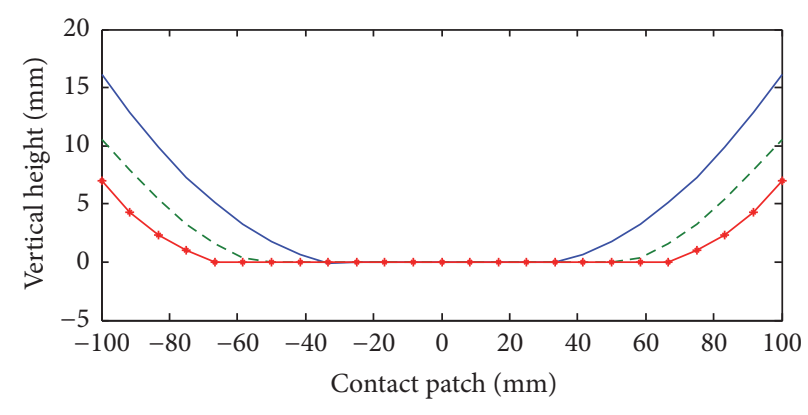

$-2.1 \mathrm{kN}$

$---5.4 \mathrm{kN}$

$\rightarrow 8.3 \mathrm{kN}$

FIgURE 6: Deformation of contact patch.
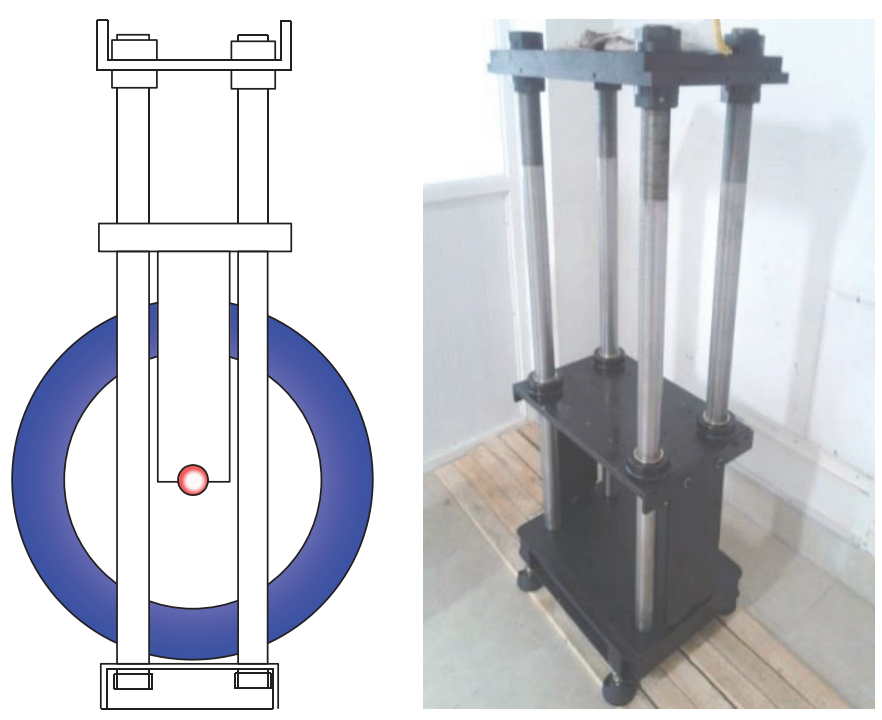

Figure 7: Contact patch test.

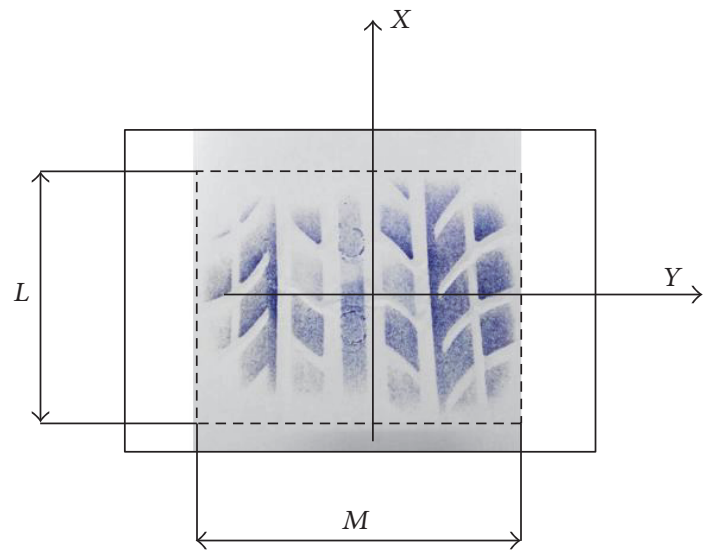

FIGURE 8: Coordinate of contact patch.

vertical model of modal parameters, analyze the sinking amount, contact of the imprinted length, force deformation, and other laws caused by the vertical load. Deformation of

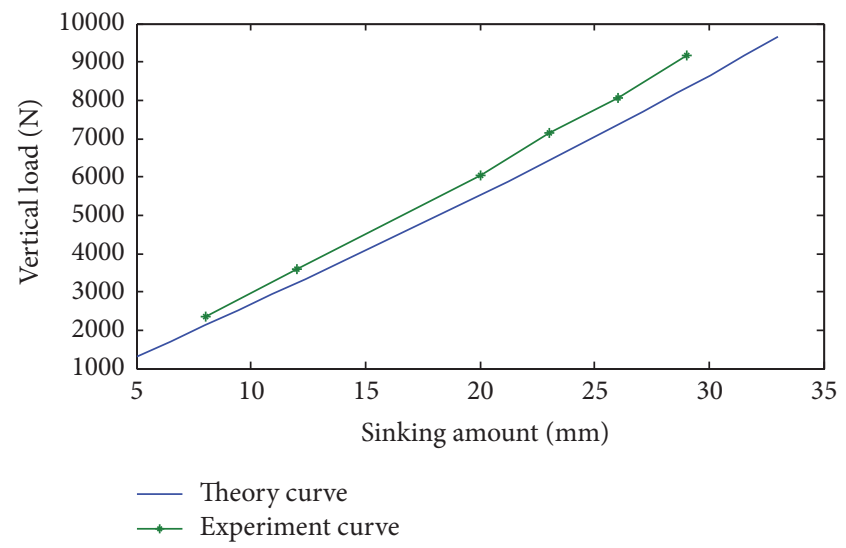

FIgURE 9: Sinking amount with loads.

carcass is the main reason for sinking amount and is also the key factor for the overall elastic deformation of tyre, and its force deformation characteristics are embodied in the modal 
parameters. According to modal test results by DASP V10 of Dongfang Institute Research Institute, tyre mold shapes render harmonic characteristics, by using trigonometric series for modal fitting and the least squares method for solving undetermined coefficients. Finally, self-developed test bench and a pressure-sensitive film Prescale TM are used in contact patch test; it can be seen that the calculation results of modal parameters are well consistent with the test bench results on contact patch length and sinking amount.

\section{Competing Interests}

The authors declare that they have no competing interests.

\section{Acknowledgments}

The research described in this paper was financially supported by National Natural Science Foundation of Youth Fund Project (61503163), Jiangsu Province "333 project" training funded project (BRA2015365), and Natural Science Foundation of the Higher Education Institutions of Jiangsu Province, China (Grant no. 16KJB130002).

\section{References}

[1] H. Pacejka, Tyre and Vehicle Dynamics, Elsevier, Amsterdam, The Netherlands, 2005.

[2] W. Yintao, F. Xijin, F. Qizhang et al., "State of the art for tire dynamical model research," Automotive Safety and Energy, vol. 5, no. 4, pp. 311-323, 2014.

[3] Z. Jide, Modern Vehicle Tyre Technology, Beijing Institute of Technology Press, Beijing, China, 2001.

[4] L. Chen, Study on Evaluation System and Method of Comprehensive Contact Performance of Radial Tyre, Jiangsu University, Zhenjiang, China, 2013.

[5] J. Svendenius, Validation of the Brush Model towards VTIMeasurement Data Recorded in Arjeplog 2006, Lund University, Lund, Sweden, 2007.

[6] M. Andersson, F. Bruzelius, J. Casselgren et al., "Road friction estimation Part II," Tech. Rep. IVSS Project 2004: 17750, 2010.

[7] K. Guo and Q. Liu, "Modelling and simulation of nonsteady state cornering properties and identification of structure parameters of tyres," International Journal of Vehicle Mechanics and Mobility, vol. 27, no. S1, pp. 80-93, 1997.

[8] J. Svendenius and M. Gäfvert, "A semi-empirical dynamic tire model for combined-slip forces," Vehicle System Dynamics, vol. 44, no. 2, pp. 189-208, 2006.

[9] D. Guang, Y. Dai, and X. Xie, "Tyre rolling model by using experimental modal parameters," Journal of Tsinghua University, vol. 43, no. 8, pp. 1138-1142, 2003.

[10] W. Guolin and W. Jianjun, "Rolling resistance finite element analysis of radial truck tyre," Computer Simulation, vol. 28, no. 11, pp. 332-334, 2012.

[11] T. G. Ebbott, R. L. Hohman, J.-P. Jeusette, and V. Kerchman, "Tire temperature and rolling resistance prediction with finite element analysis," Tire Science and Technology, vol. 27, no. 1, pp. 2-21, 1999.

[12] A. Gallrein and M. Bäcker, "CDTire: a tire model for comfort and durability applications," Vehicle System Dynamics, vol. 45, no. 1, pp. 69-77, 2007.
[13] G. Dihua, Z. Xiangsheng, and F. Chengjian, "An analysis on different types of damping in tyre dynamic model and their effects on rolling resistance and dynamic responses of tyre," Vehicle Engineering, vol. 28, no. 7, pp. 643-646, 2006.

[14] G. Dihua, P. Hui, and F. Jiancheng, "Study on tyre modal test analysis ," Vehicle Engineering, vol. 27, no. 6, pp. 691-695, 2005.

[15] D. Yining, Tyre Rolling Model by Using Experimental Modal Parameters, Tsinghua University, Beijing, China, 2002.

[16] K. Chittilla, Y. Yeola, A. Tiwari, and R. Rajamanickam, "Effect of excitation methods on experimental modal analysis of passenger car tire," SAE Technical Papers, vol. 12, Article ID 2013-01-2854, 5 pages, 2013.

[17] L. H. Yam, D. H. Guan, and A. Q. Zhang, "Three-dimensional mode shapes of a tire using experimental modal analysis," Experimental Mechanics, vol. 40, no. 4, pp. 369-375, 2000.

[18] J. Shang, D. Guan, and L. H. Yam, "Study on tire dynamic cornering properties using experimental modal parameters," Vehicle System Dynamics, vol. 37, no. 2, pp. 129-144, 2002.

[19] D. Zhaolong, A Quantitative Study on the Model of Tyre Sidslip Characteristics of Modal Parameters, Tsinghua University, Beijing, China, 2006.

[20] W. Zhenfeng, Research on Key Problems of Tyre Model Based on Modal Parameters, Yanshan University, Qinhuangdao, China, 2012.

[21] Z. Peng, Tyre Rolling Model Research Based on Modal Parameters, Yanshan University, Qinhuangdao, China, 2013. 


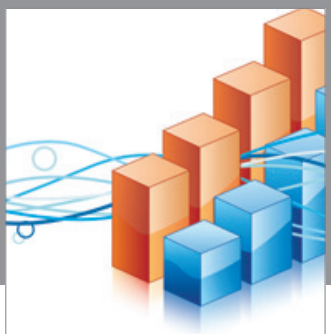

Advances in

Operations Research

vatem alat4

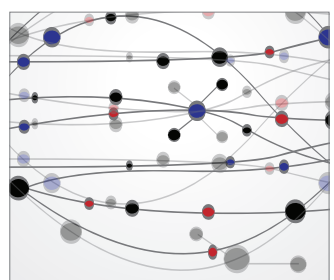

\section{The Scientific} World Journal
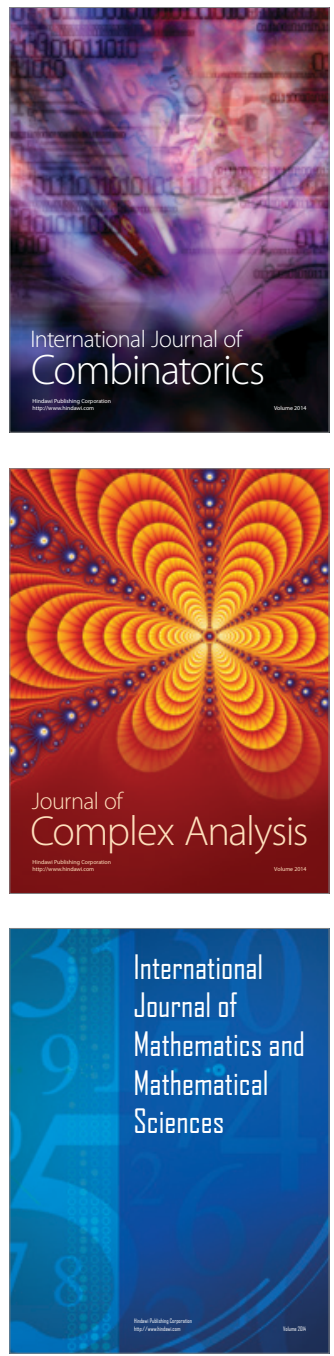
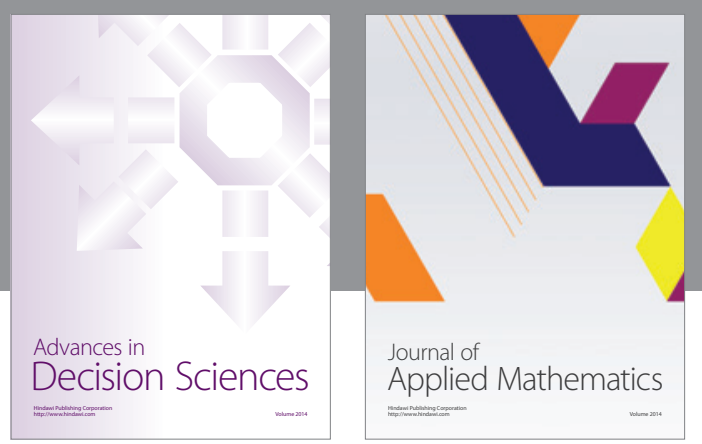

Algebra

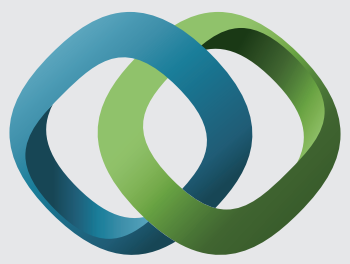

\section{Hindawi}

Submit your manuscripts at

https://www.hindawi.com
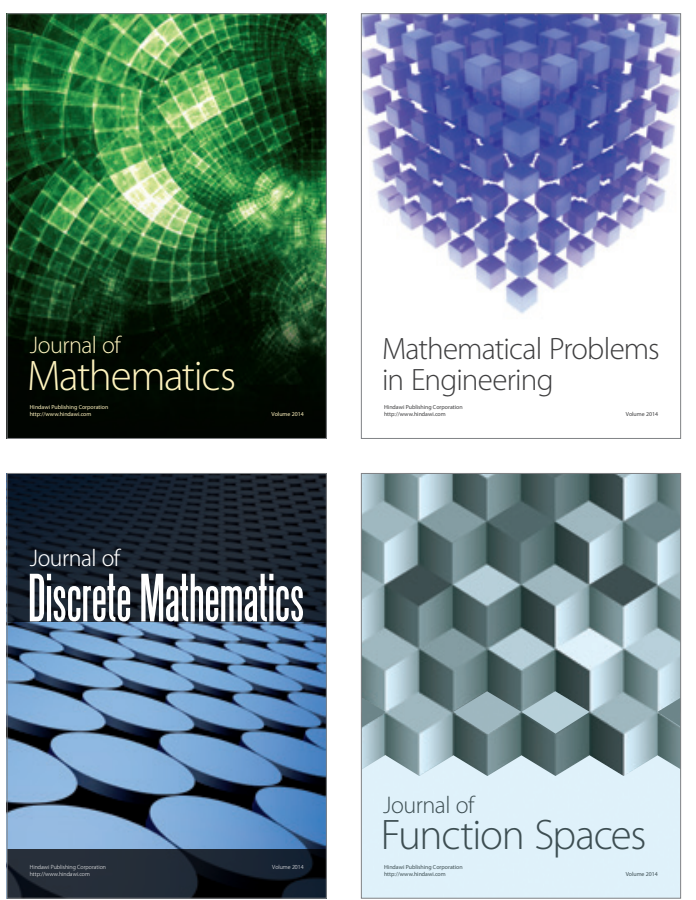

Mathematical Problems in Engineering
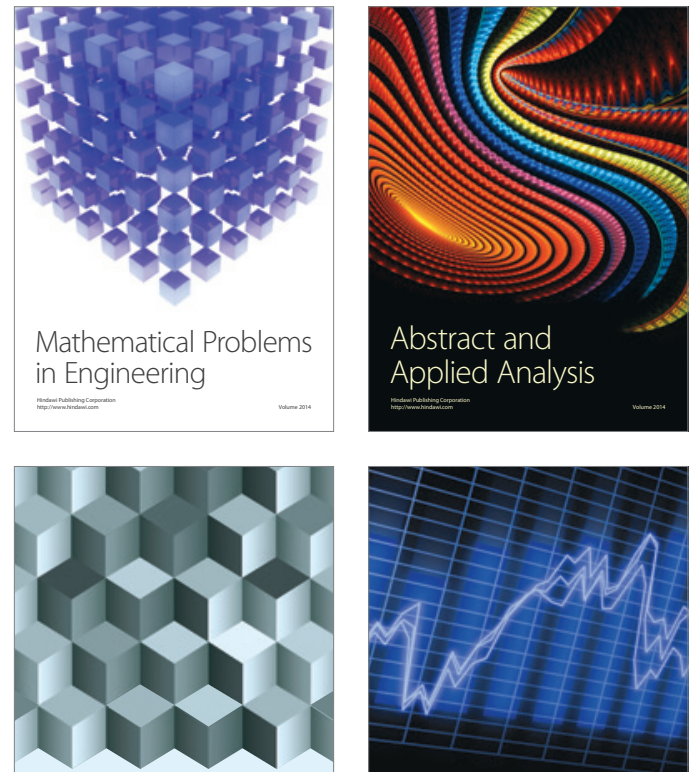

Journal of

Function Spaces

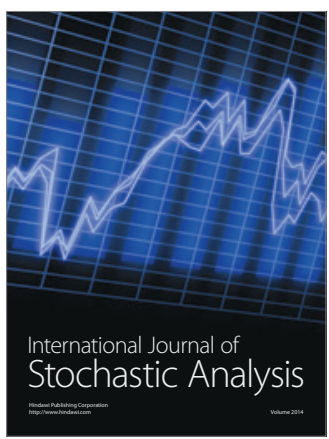

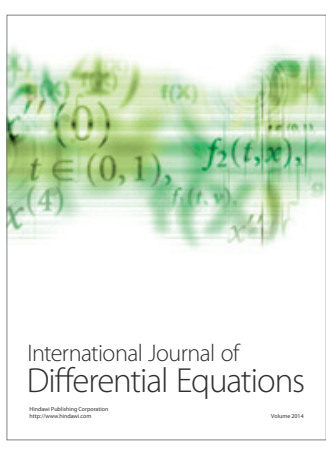
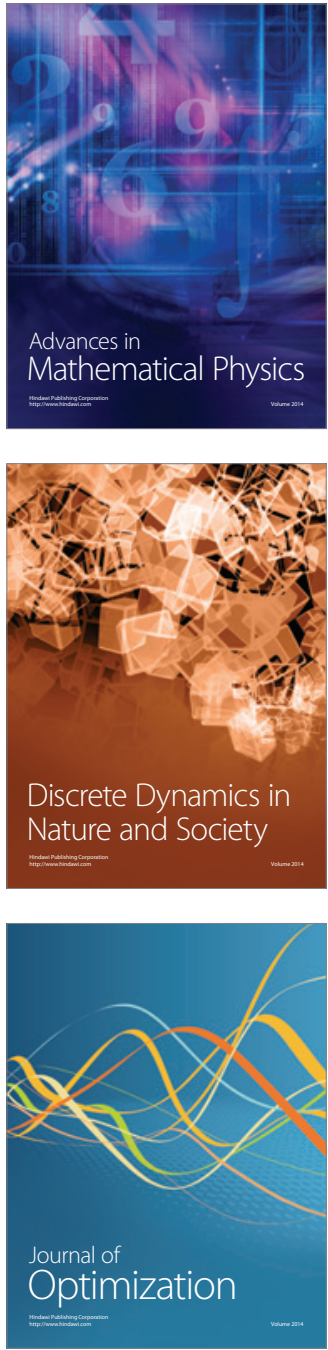